\title{
Speciation Of Chromium In Soils, Plants And Waste Water At A Ferrochrome Slag Dump In Gweru
}

\author{
Mandina Shadreck ${ }^{1}$, Mugadza Tawanda ${ }^{2}$ \\ ${ }^{I}$ Department of Educational Foundations, Management and Curriculum Studies, Midlands State University, P. \\ Bag 9055, Gweru, Zimbabwe \\ ${ }^{2}$ Department of Chemical Technology, Midlands State University, P. Bag 9055, Gweru, Zimbabwe
}

\begin{abstract}
This study assessed chromium pollution in soils, plants, water and slag from a ferrochrome smelting plant in Gweru, Zimbabwe. Speciation of chromium in plant leaves, soil and slag samples was carried out by selective leaching of $\mathrm{Cr}$ (VI) using a sodium carbonate leaching procedure prior to the spectrophotometric determination of $\mathrm{Cr}(\mathrm{VI})$. Total $\mathrm{Cr}$ and $\mathrm{Cr}$ (III) concentration in the samples were analyzed by Flame Atomic Absorption Spectroscopy following aqua regia and oxidative acid digestion. The average concentration of $\mathrm{Cr}$ (VI) in soil $(1.0301 \pm 0.0854) \mu g g^{-1}$ and plant $(0.3372 \pm 0.0168) \mu g g^{-1}$ samples were higher relative to control samples with the contamination factors of 3.2 and 3 , respectively. Leaching of hexavalent $\mathrm{Cr}$ indicated its poor solubility in water $\left(0.00141 \mu^{-1} g^{-1}\right.$.
\end{abstract}

Key words: Speciation; Chromium; Ferrochrome slag; leaching

\section{Introduction}

Contamination of the environment by toxic heavy metal has become one of the pressing problems in the world in recent times due to health risks on humans and animals (Mahvi, 2008). As revealed by toxicological studies (Elci, 2010), the degree of toxicity of metals depends on their chemical forms and oxidation states. The strong dependence of the toxicity of heavy metals upon their chemical forms has led to an increasing interest in the qualitative and quantitative determination of specific metal species. Speciation is therefore an important research topic in present day analytical studies. The speciation forms of chromium $(\mathrm{Cr}$ (III) and $\mathrm{Cr}(\mathrm{VI})$ ) are a major cause for concern because some of their compounds are highly toxicity to aquatic and terrestrial organisms, including humans (Zayed and Terry, 2003). These two species show different chemical, physico-chemical and biochemical properties (Kotas and Stasicka, 2000). Cr (VI) species are more soluble, mobile and bioavailable than Cr (III) species (Kotas and Stasicka, 2000). Cr (III) is essential for the maintenance of the normal glucose tolerance factor whereas $\mathrm{Cr}(\mathrm{VI})$ is a well-known carcinogen (Andjelković, 2012). Consequent of its solubility and mobility, $\mathrm{Cr}$ (VI) in soils can be leached into surface water or groundwater, and taken up by plants (Wang et al.,2011) hence $\mathrm{Cr}$ (VI) incurs a significant risk to human health when released into the soil environment (Huang, 2009).

\section{Literature Review}

Chief environmental pollutants are generated from metallurgical industrial wastes (Tiwary et al.,2005) like slag that has been treated, recycled and used worldwide. Large volumes of the slag come from ferrochrome production and is dumped without any pollution prevention, control or remediation measures (Hattingh and Friend, 2003). These slags pose a significant threat to human life and the environment, for example, hexavalent $\mathrm{Cr}, \mathrm{Fe}$ and Mn (Pillay et al., 2003). These metals are known to bioaccumulate in soil and highly persistent in soil and enter food chains through plants or animals (Dosumu, 2003). Further, it has the potential to produce leachates that pollute surface and groundwater resources.

Leaching of $\mathrm{Cr}(\mathrm{VI})$ from the ferrochrome slag causes sustainable contamination to the environment (Shah,1984). Lind et al., (2001) and Pillay et al., (2003) indicated that there is gradual oxidation of trivalent to hexavalent chromium when the slag is exposed to atmospheric oxygen. This releases the more mobile and toxic $\mathrm{Cr}$ (VI) into the environment.

In order to recover chromium metal, slag is crushed and then subjected to wet magnetic and gravimetric methods (Riekkola-Vanhanen, 1999; Mashanyare and Guest, 1997). However, slags can contain high levels of extractable toxic elements which could pose environmental problems. In a study dealing with the process water of metal recovery from slag, (Coetzer, Giesekke and Guest, 1997) it has been reported that Cr has been detected as chromate in the processing water, which may create chromium pollution. The milling practice of ferrochromium slag alters the oxidation state of chromium, releasing $\mathrm{Cr}$ (VI) into the environment (Buekes and Guest, 2001).

The direct deposition of slag onto the ground and discharge of wastewater into the sewage system that runs through agricultural land by a ferroalloy plant in the Hunan Province of China has resulted in long-term 
soil and vegetable contamination (Wang et al. 2011). The total chromium content in the soil ranged from 90 to $6200 \mathrm{mg} / \mathrm{kg}$ while hexavalent chromium ranged from 0.1 to $252 \mathrm{mg} / \mathrm{kg}$. The vegetables sampled in the study contained more than 4 times the permissible amount of chromium $(2.1-18.8 \mathrm{mg} / \mathrm{kg}$ dry weight). A health risk assessment based on estimated site-specific exposure to local vegetables and soil concluded there were elevated cancer risks as high as $6.6 \times 10^{-6}$ for agricultural exposure and $2.2 \times 10^{-5}$ for residential exposure to soil. (Wang et al. 2011).

A study by (Erdem et al. 2005) has shown that conversion of $\mathrm{Cr}$ (III) to toxic $\mathrm{Cr}$ (VI) during high temperature chromite smelting also results in contaminated slag (waste produced during separation of ferrochrome from ore). (Erdem et al. 2005) further note that metal recovery from slag results in production of contaminated water that may require treatment. Their studies on chromium leaching from $\mathrm{FeCr}$ slag have shown that sequential washing of ferrochrome slag resulted in $\mathrm{Cr}(\mathrm{VI})$ leaching from crushed slag $\mathrm{Cr}(\mathrm{VI})(610 \mathrm{ug} / \mathrm{L})$ and ground slag (3800 ug/L) (Erdem et al. 2005).

These studies indicate the hazardous nature of ferrochrome slag due to its potential to leach out heavy metals. Leachability of heavy metals affects both the environment and human health. As a result there is need to establish the contamination levels of $\mathrm{Cr}(\mathrm{VI})$ in environmental samples around the ferrochrome slag dump.

The aim of this study is therefore to investigate the speciation of $\mathrm{Cr}$ in soils, plants and waste water at a ferrochrome smelter slag dump in order to establish its environmental contamination levels. This study in Gweru is the first of its nature and has never been reported before.

\section{Previous Work}

Research work by Pumure et al., (2003) focused on characterization of particulate matter emission form the stack at a ferrochrome smelter in Zimbabwe as well as the extent of soil contamination by the dust deposited around the smelter in the generally prevailing southeasterly wind direction around the smelter. Studies in South Africa (Sedumedi et al., 2009) also investigated the impact of a ferrochrome smelter on the contamination of its environment with toxic hexavalent chromium, $\mathrm{Cr}(\mathrm{VI})$, by analyzing smelter dusts, soil, grass and tree barks. No study has been conducted in Zimbabwe to investigate the impact of the ferrochrome slag dump on its immediate environment.

\subsection{Equipment}

\section{Methodology}

A Shimadzu Spectra AA 6800 Flame Atomic Absorption Spectrometer was used for the determination of total chromium measurements. All measurements were made at the $357.9 \mathrm{~nm}$ analytical line, with a $0.7 \mathrm{~nm}$ band pass using a chromium hollow cathode lamp source operating at $25 \mathrm{~mA}$. A Shimadzu UV - 1700 pharma spec spectrophotometer was used for the determination of $\mathrm{Cr}(\mathrm{VI})$. All measurements were done at $540 \mathrm{~nm}$.

\subsection{Reagents and Materials}

All solutions were prepared from high purity analytical-reagent grade compounds from Skylabs, Zimbabwe, using distilled water. All the plastic and glassware were cleaned by soaking in dilute $10 \% \mathrm{HNO}_{3}$ and were rinsed with distilled water prior to use. Standard stock solutions containing $1000 \mathrm{mgL}^{-1} \mathrm{Cr}$ (VI) and $\mathrm{Cr}$ (III) were prepared by dissolving appropriate amounts of anhydrous potassium dichromate, $\mathrm{K}_{2} \mathrm{Cr}_{2} \mathrm{O}_{7}$ (Merck) and $\mathrm{CrCl}_{3} \cdot 6 \mathrm{H}_{2} \mathrm{O}$ respectively in distilled water. $0.1 \mathrm{M} \mathrm{Na}_{2} \mathrm{CO}_{3}$ was prepared by dissolving appropriate amounts of sodium carbonate in distilled water. All chromium working standards were freshly prepared.

\subsection{Samples and sample preparation \\ 4.3.1 Samples}

Ferrochrome slag samples were supplied by Zimbabwe Alloys ferrochrome smelter, Gweru, Zimbabwe. Plant leaves (vallisneira spiralis) were collected from within $20 \mathrm{~m}$ radius of the slag disposal site. The samples were placed in plastic bags, and later the leaves were washed thoroughly using tap water to remove soil or debris. They were further washed with distilled water, dried at room temperature on a sheet of paper, then oven-dried at $80^{\circ} \mathrm{C}$ and later ground in a mortar to 60 mesh size particles. The ground samples were then stored in a clean, dry, stoppered glass container (Elci et al., 2010). Control plant samples were collected from an uncontaminated area in Mkoba 1 surburb Gweru.

Soils samples were collected from the same area. Soil sapling was restricted to the upper soil layer within a thickness of $20 \mathrm{~cm}$ at four sampling locations around the slag dump. A composite slag sample representative of the whole slag heap was taken at Zimbabwe Alloys slag disposal site All soil samples were airdried at room temperature and pulverized to a particle size less than $75 \mu \mathrm{m}$ (Sedumedi et al., 2009). Control soil samples were also collected in an uncontaminated area of Mkoba surbub in Gweru, Zimbabwe whose soil type resembled that near the slag dump. About $500 \mathrm{~g}$ of soil samples was taken from each sampling location. 
Waste water samples were collected from the metals recovery plant at the slag dump, slimes dam and at the point of discharge. The samples were placed in clean plastic bottles that had initially been rinsed three times with the wastewater and preserved with $1 \mathrm{~cm}^{3}$ of dilute $\mathrm{HNO}_{3}$ (Ibrahim, 2008).

\subsubsection{Determination of $\mathrm{Cr}(\mathrm{VI})$}

Approximately $0.25 \mathrm{~g}$ sample of ground leaves was weighed into a glass beaker and $25.0 \mathrm{~cm}^{3}$ of $0.1 \mathrm{M}$ $\mathrm{Na}_{2} \mathrm{CO}_{3}$ was added and the mixture was boiled on a hot plate for $15 \mathrm{~min}$. After filtration through Whatman No. 45 filter paper, the precipitates were washed several times with $0.1 \mathrm{M} \mathrm{Na}_{2} \mathrm{CO}_{3}$ (Panichev et al., 2005). The final volumes of the sample solutions were diluted to $25.0 \mathrm{~cm}^{3}$ with distilled water prior to analysis by the 1.5 diphenyl carbazide method at $540 \mathrm{~nm}$ (Clesceri et al., 1998). The same procedure was also applied to $0.25 \mathrm{~g}$ of soil and slag samples.

For the determination of $\mathrm{Cr}(\mathrm{VI})$ in waste water, the wastewater samples were filtered through a Whatman No. 45 filter paper. An aliquot of $50 \mathrm{~cm}^{3}$ was taken from each sample and then acidified with $5 \mathrm{~cm}^{3}$ of $0.2 \mathrm{M}$ Sulfuric acid up to a mark of $50 \mathrm{~cm}^{3}$. The samples were analysed for chromium (VI) by the a calorimetric method using 1,5 diphenyl carbazide reagent $\left(250 \mathrm{mg} 1.5\right.$ diphenyl carbazide in $50 \mathrm{~cm}^{3}$ of acetone) as complexing agent, which reacts with $\mathrm{Cr}$ (VI), forming a colour complex that absorbs light at $540 \mathrm{~nm}$. (Clesceri et al., 1998).

\subsubsection{Determination of $\mathrm{Cr}$ (III) in plant samples}

The precipitates, which were left after the filtration of samples treated with $0.1 \mathrm{M} \mathrm{Na} \mathrm{NaO}_{3}$, were transferred from the filter paper to a $250 \mathrm{~cm}^{3}$ conical flask and digested with $5.0 \mathrm{~cm}^{3}$ mixture of concentrated nitric acid (65\%) and perchloric acid (70\%) (Mandiwana et al., 2007). When digestion was complete, $10 \mathrm{~cm}^{3}$ of $0.5 \mathrm{M} \mathrm{HCl}$ was added to redissolve the residue and the resultant solution filtered into a $50 \mathrm{~cm}^{3}$ volumetric flask, brought to the mark using distilled water and the resulting solution was then analyzed by FAAS. The same procedure was applied to soil and slag samples.

\subsubsection{Determination of total $\mathrm{Cr}$ in samples}

$2 \mathrm{~cm}^{3}$ of $\mathrm{H}_{2} \mathrm{O}_{2}$ (ca. $30 . \%$ ), $2 \mathrm{~cm}^{3}$ of concentrated $\mathrm{HClO}_{4}$ and $4 \mathrm{~cm}^{3}$ of concentrated $\mathrm{HNO}_{3}$ were added to $0.50 \mathrm{~g}$ of the ground-dry leaves. The mixture was heated at $170^{\circ} \mathrm{C}$ for $3 \mathrm{~h}$. The digest was allowed to cool and then $2 \mathrm{~cm}^{3}$ of $\mathrm{H}_{2} \mathrm{SO}_{4}$ and $8 \mathrm{~cm}^{3}$ of the mixture containing $4 \mathrm{~cm}^{3}$ of conc. $\mathrm{HNO}_{3}, 2 \mathrm{~cm}^{3}$ of conc. $\mathrm{HClO}_{4}$ and $2 \mathrm{~cm}^{3}$ $\mathrm{H}_{2} \mathrm{O}_{2}$ (ca. 30.\%) were added. The mixture was centrifuged at $2500 \mathrm{rpm}$ for 5 min. The supernatant was made up to $10 \mathrm{~cm}^{3}$ using distilled water and analyzed using FAAS (Divrikli, et al, 2003).

For soil and slag samples, $10 \mathrm{~cm}^{3}$ of aqua regia was added to $0.5-1.0 \mathrm{~g}$ portions of dry soils and dry slag. The resulting mixture was heated at $60-70^{\circ} \mathrm{C}$ for $4 \mathrm{~h}$ (Elci et al., 2010). After the solution was cooled, the solution was filtered through Whatman no. 45 filter paper. The filtrate was diluted to $25 \mathrm{~cm}^{3}$ with distilled water for analysis by FAAS.

\subsubsection{Leachability of chromium (VI) from slag samples}

To estimate the leachability of chromium (VI) with water, a $0.25 \mathrm{~g}$ sub-sample was transferred into three conical flasks and $25.0 \mathrm{~cm}^{3}$ distilled water was added to each flask. The contents of the flasks were periodically mechanically shaken for $24 \mathrm{~h}, 48 \mathrm{~h}$ and $72 \mathrm{~h}$ (Sedumedi et al., 2009). The sample solution was filtered through Whatman no. 45 filter paper to remove $\mathrm{Cr}$ (III) species that may be trapped in the colloidal suspension prior to determination of $\mathrm{Cr}$ (VI) by the 1.5 diphenyl carbazide method.

\subsection{Determination of $\mathbf{C r}$ in samples}

\section{Results And Discussion}

Plant, soil and slag samples were analyzed by the leaching procedure using $\mathrm{Na}_{2} \mathrm{CO}_{3}$ after the determination of chromium (VI) by ultraviolet visible spectrophotometry. The results obtained are shown in Table 1. The results indicate that samples were contaminated with significant levels of $\mathrm{Cr}(\mathrm{VI})$ as compared with control samples taken from the uncontaminated area with a contamination factor of 3 . However the levels of $\mathrm{Cr}$ (VI) in the samples were lower than normal chromium concentrations, $1 \mu \mathrm{gg}^{-1}$ in plants (Elci et al., 2010).

Table 1 Determination of Levels of Chromium in plants $(n=3)$

\begin{tabular}{lccc}
\hline Sample & {$[\mathrm{Cr}(\mathrm{VI})] / \mu \mathrm{gg}^{-1}$} & {$[\mathrm{Cr}(\mathrm{III})] / \mu \mathrm{gg}^{-1}$} & {$[\mathrm{Total} \mathrm{Cr}] / \mu \mathrm{gg}^{-1}$} \\
$\mathrm{P}_{1}$ & $0.325 \pm 7 \times 10^{-4}$ & $0.1161 \pm 1 \times 10^{-4}$ & $0.4184 \pm 2 \times 10^{-4}$ \\
$\mathrm{P}_{2}$ & $0.3544 \pm 4 \times 10^{-4}$ & $0.0664 \pm 4 \times 10^{-4}$ & $0.4424 \pm 5 \times 10^{-4}$ \\
$\mathrm{P}_{3}$ & $0.3488 \pm 1 \times 10^{-4}$ & $0.0781 \pm 2 \times 10^{-4}$ & $0.4359 \pm 1 \times 10^{-4}$ \\
$\mathrm{P}_{4}$ & $0.3207 \pm 2 \times 10^{-4}$ & $0.0991 \pm 2 \times 10^{-4}$ & $0.4592 \pm 2 \times 10^{-4}$ \\
Control & $0.1227 \pm 2 \times 10^{-4}$ & $0.0411 \pm 1 \times 10^{-4}$ & $0.1645 \pm 5 \times 10^{-4}$ \\
Contamination Factor (CF) & 3 & 2.2 & 2.7 \\
\hline
\end{tabular}


$\mathrm{Cr}$ (VI) in soil samples showed that the levels in soil were also higher than in control samples with a contamination factor of 3.2 (Table 2). However, the levels of $\mathrm{Cr}$ (VI) in these samples were lower than the maximum environmental acceptable concentration of $20 \mathrm{\mu gg}^{-1}$ that is allowed on hazardous waste (DWARF, 1998)

Table 2 Determination of levels of Chromium in soil $(n=3)$

\begin{tabular}{lccc}
\hline Sample & {$[\mathrm{Cr}(\mathrm{VI})] / \mu \mathrm{gg}^{-1}$} & {$[\mathrm{Cr}(\mathrm{III})] / \mu \mathrm{gg}^{-1}$} & {$[\mathrm{Total} \mathrm{Cr}] / \mu \mathrm{gg}^{-1}$} \\
$\mathrm{~S}_{1}$ & $0.9813 \pm 3 \times 10^{-4}$ & $0.1304 \pm 2 \times 10^{-4}$ & $1.1118 \pm 6 \times 10^{-4}$ \\
$\mathrm{~S}_{2}$ & $1.0204 \pm 2.5 \times 10^{-3}$ & $0.1436 \pm 2 \times 10^{-4}$ & $1.1777 \pm 2 \times 10^{-4}$ \\
$\mathrm{~S}_{3}$ & $1.0847 \pm 6 \times 10^{-4}$ & $0.1115 \pm 3 \times 10^{-4}$ & $1.1821 \pm 3 \times 10^{-4}$ \\
$\mathrm{~S}_{4}$ & $1.0140 \pm 4 \times 10^{-4}$ & $0.1539 \pm 3 \times 10^{-4}$ & $1.1784 \pm 2 \times 10^{-4}$ \\
Control & $0.3248 \pm 1.1 \times 10^{-3}$ & $0.1204 \pm 3 \times 10^{-4}$ & $0.4501 \pm 1 \times 10^{-4}$ \\
$\mathrm{CF}$ & 3.2 & 1.12 & 2.6 \\
\hline
\end{tabular}

Figure 1 shows a comparative distribution of the levels of $\mathrm{Cr}(\mathrm{VI})$ in plants and soils. The average concentration of $\mathrm{Cr}(\mathrm{VI}), 0.3372 \mu \mathrm{gg}^{-1}$, in plant leaves growing around the slag dump is approximately one-third of that of $\mathrm{Cr}$ (VI), $1.0301 \mu \mathrm{gg}^{-1}$, in polluted soil. The findings are in agreement with Mandiwana et al., (2007) who found out that the concentration of water soluble $\mathrm{Cr}(\mathrm{VI})$ in soil is always higher than that in the respective plant. Consequently the level of $\mathrm{Cr}$ (VI) in soil can be used as an indicator to estimate the maximum levels of this pollutant that can be accumulated by plants.

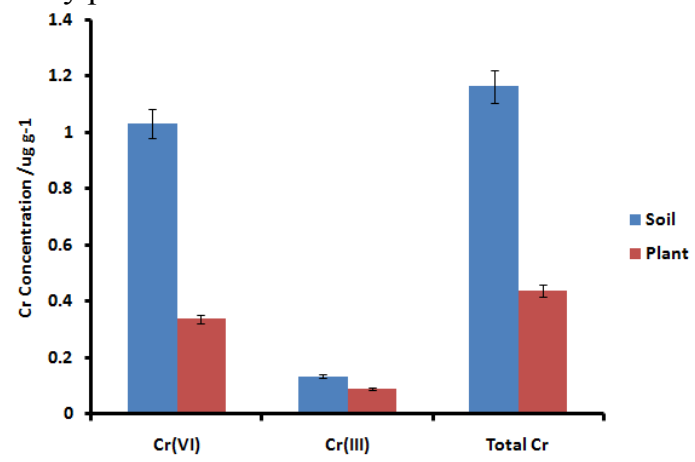

Figure 1. Comparative Distribution of $\mathrm{Cr}$ in soils and plants

To investigation the environmental impact of the ferrochrome slag dump, the concentration of $\mathrm{Cr}$ (VI) in plants as a function of distance from the slag dump was determined. The results are shown in Figure 2. The findings reveal that the levels of $\mathrm{Cr}$ (VI) in plants decreases as a function of the distance from the slag dump. The findings are consistent with those of Sedumedi et al., (2009), Pumure et al., (2003) and Huang et al., (2009) who noted a decrease in $\mathrm{Cr}$ in soils with distance from the ferrochrome smelter.

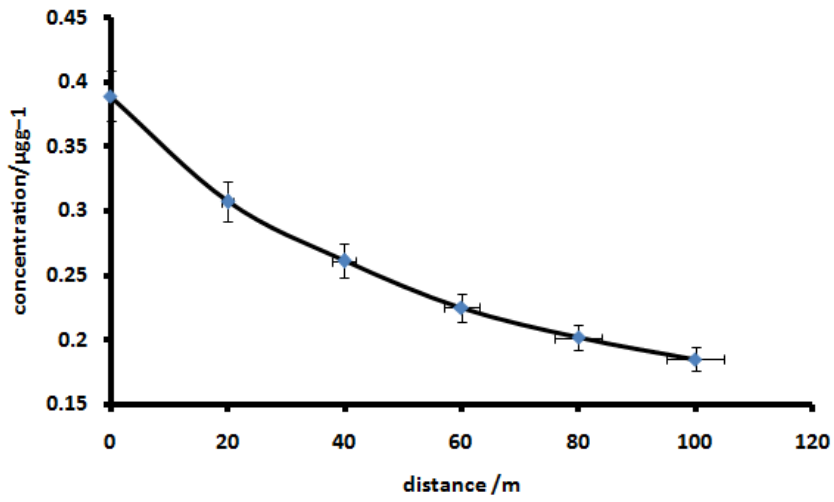

Figure 2: Variation of $\mathrm{Cr}$ (VI) concentration in plants as a function of distance from the slag dump

In order to assess the potential for heavy metal leaching from the slag, a determination of $\mathrm{Cr}$ ( $\mathrm{VI}$ ) and total $\mathrm{Cr}$ was done. The results are shown in Table 3. The results indicate that the slag contains high levels of $\mathrm{Cr}$ (III) and very trace levels of $\mathrm{Cr}$ (VI). The findings are consistent with those of Niemella and Kauppi (2005) who found out that $\mathrm{Cr}$ mainly exists as $\mathrm{Cr}_{2} \mathrm{O}_{3}$ (chrome oxide) bound in the spinel phases. They further noted that the binding efficiency of chrome can be estimated by means of a "factor sp", which is about 30 for ferrochrome slag. If the "factor sp" is higher than 5 , the solubility of chrome decreases to a very low level. The formation of soluble chrome salts, especially of hexavalent chrome, is thus implausible in the strongly reducing conditions of the smelting furnace, but chrome is trivalent or bivalent and metallic does occur. The findings further confirm 
previous work by Chaurand et al.,(2006) who noted little or no release of $\mathrm{Cr}$ which remains in its initial trivalent form, that is less toxic, even during leaching.

Table. 3. Levels of $\mathrm{Cr}$ in slag

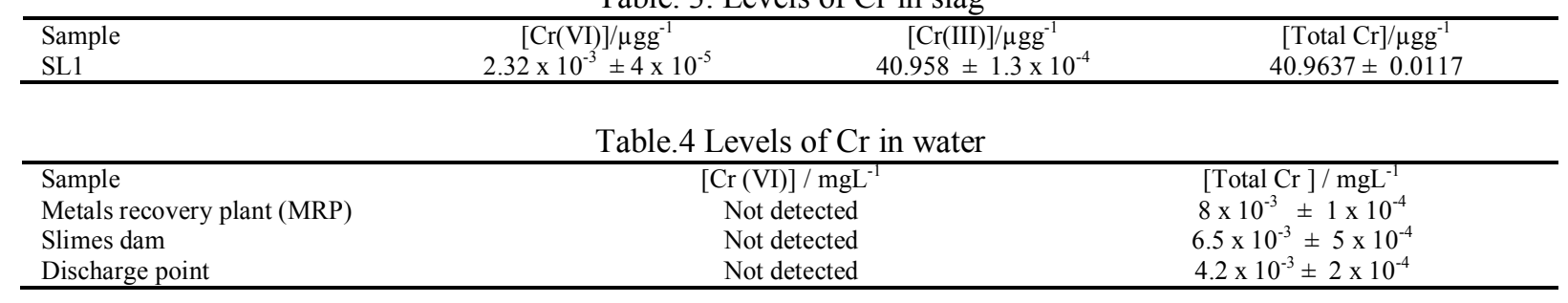

Table 4 shows the levels of total $\mathrm{Cr}$ in water. Total $\mathrm{Cr}$ concentrations ranged from $4.2 \mu \mathrm{g} / \mathrm{L}$ to $8 \mu \mathrm{g} / \mathrm{L}$ while $\mathrm{Cr}$ (VI) was not detected in all the water samples. The Cr levels in water do not exceed the maximum acceptable level for $\mathrm{Cr}$ (total) in drinking water $\left(50 \mu \mathrm{g} . \mathrm{L}^{-1}\right)$, according to the EU Directive) and (EC, Council Directive (98/83/EC). The water samples were collected at the metals recovery plant at the slag dump. The findings are consistent with those of Coetzer, Giesekke and Guest (1997) who developed a successful jigging process to recover ferrochromium metal from waste dumps. The potential for generating $\mathrm{Cr}$ (VI) during this operation has been investigated. The tests conducted indicate that there is no evidence for the continual release of $\mathrm{Cr}(\mathrm{VI})$ during the jigging operation. This could explain why no $\mathrm{Cr}$ (VI) was detected in the water from the metals recovery plant.

\subsection{Leachability of chromium(VI) with water} Table 5. Water soluble chromium (VI) in slag

\begin{tabular}{lc}
\hline Time $/ \mathrm{hr}$ & {$[\mathrm{Cr}(\mathrm{VI})] / \mathrm{\mu gg}^{-1}$} \\
24 & $1.3 \times 10^{-3} \pm 3.5 \times 10^{-5}$ \\
48 & $1.4 \times 10^{-3} \pm 2 \times 10^{-5}$ \\
72 & $1.41 \times 10^{-3} \pm 2 \times 10^{-4}$ \\
\hline
\end{tabular}

To determine the amount of leached $\mathrm{Cr}$ (VI), the slag samples were added to water, shaken as earlier stated and analyzed by the 1.5 diphenyl carbazide method. Results shown in Table 5 indicate that $\mathrm{Cr}(\mathrm{VI})$ in slag samples is not significantly soluble in water. The highest amount leached was $1.41 \times 10^{-3} \mu^{\mathrm{g} \mathrm{g}^{-1}}$ and these findings are in agreement with those of Tanskanen and Makkonen (2005). This is due to the mineralogical capture of chrome into the stable spinel phase and of the structural encapsulation of the dispersed crystals inside an impermeable and chemically stable glass phase. This concentration does not exceed the maximum acceptable environmental risk concentration of $20 \mu \mathrm{g} \mathrm{g}^{-1}$ allowed for the disposal of waste (Barcan and Kovnatsky, 1998). Erdem et al., (2005) also established that the leaching of $\mathrm{Cr}$ (VI) from slag to ground water was very slight. According to the Toxicity Characteristic Leach Procedure (TCLP) tests, (Pillay et al., 2003) it can be concluded that the ferrochromium slag is not a potential pollutant.

\subsection{Method validation}

The accuracy of the methods applied in the leaching or/and digestions of $\mathrm{Cr}$ in samples was validated by the analysis of spiked samples performed using standard solutions. The testing was done on soil samples following the stated sample pretreatment method (Sedumedi et al., 2009). The validity of the method was checked with the amount added and the amount recorded by the FAAS for total chromium while for $\mathrm{Cr}$ (VI) method validity was checked by the amount recorded by the UV/vis.

The recovery of total $\mathrm{Cr}$ in the soil samples ranged between $95.85-96.05 \%$, respectively Recoveries for $\mathrm{Cr}$ ( $\mathrm{VI}$ ) in the two soil samples were found to be $98.05 \%$ and $98.25 \%$, respectively. The good recovery values obtained confirm the accurate determination of $\mathrm{Cr}(\mathrm{VI})$ and total chromium by Uv/vis and FAAS, respectively.

\section{Conclusions}

Soil and plant samples collected at the slag dump were contaminated with significant levels of $\mathrm{Cr}$ (VI) as compared with control samples taken from the uncontaminated area. The amount of $\mathrm{Cr}$ in these samples was found to be within the specified limits. The findings reveal that level of $\mathrm{Cr}(\mathrm{VI})$ in plants decreases as a function of the distance from the slag dump. The contamination factors (CF) were found to be 3 (plant) and 3.2 (soil) for $\mathrm{Cr}$ (VI), respectively; 2.2 (plant) and 1.22 (soil) for Cr (III), respectively and 2.7 (plant) and 2.6 (soil) for total $\mathrm{Cr}$, respectively. The $\mathrm{CF}$ in plants is the same as that in soils for $\mathrm{Cr}(\mathrm{VI})$ and total $\mathrm{Cr}$ while the $\mathrm{CF}$ is two times higher in plants than soils for Cr (III). Slag was also found to contain high levels of Cr (III). Data on the leaching of hexavalent $\mathrm{Cr}$ with water showed that the $\mathrm{Cr}$ (VI) in slag is not very soluble in water. This concentration does not exceed the maximum acceptable environmental risk. 


\section{Future Scope}

Further research work should focus on leaching tests with simulated acid rain to determine the extent of $\mathrm{Cr}$ (VI) leaching in event that acid rain falls. Ground water source at the slag dump need to be monitored regularly to ascertain the contamination of the water with $\mathrm{Cr}(\mathrm{VI})$.

\section{References}

[1]. Andjelković, D.H., Andjelković, T.D., Nikolić, R.S., Purenović, M.M., Blagojević, S.D., Bojić, A.L.J and Ristić, M.M. (2012) Leaching of chromium from chromium contaminated soil - a speciation study and geochemical modeling. Journal of the Serbian Chemical Society, 77 (1) 119-129

[2]. Barcan V. and Kovnatsky E. (1998) Soil surface geochemical anomaly around the copper-nickel metallurgical smelter. Water, Air and Soil Pollution, 103: 197- 218.

[3]. Beukes, J.P. and Guest, R.N. (2001) Cr(VI) generation during milling. Mineral Engineering, 14, 423 - 430

[4]. Chaurand, P., Rose, J., Proux, O., Hazemann, J. L., Briois, V., Salome, M., Susini, J., Ferrasse, J. H., Borschneck, D., Bott ero, J. Y. (2006). In Environmental impact of steel slag reused as aggregates in road manufacturing: Molecular mechanisms of chromium and vanadium release, 13th International Conference on X-Ray Absorption Fine Structure (XAFS13), Stanford, CA, Jul 09-14,; Hedman, B.; Painetta, P., Eds. Amer Inst Physics: Stanford, CA, 2006; pp 199-201.

[5]. Clesceri, L.S., Eaton, A.D. and Greenberg, A.E. (1998) Standard methods for the Examination of Water and Wastewater. 20th Edn., American Public Health Association, Washington, D.C., pp: 1220.

[6]. Coetzer, G., Giesekke, E. W. and Guest, R. N. (1997) Hexavalent chromium in the recovery of ferrochromium from slag. Canadian Metallurgical Quarterly, 36 (4), 261-268

[7]. Department of Water Affairs and Forestry (DWAF) (1998) Minimum requirements for the handling, classification and disposal of hazardous waste, 2 nd edition, South Africa.

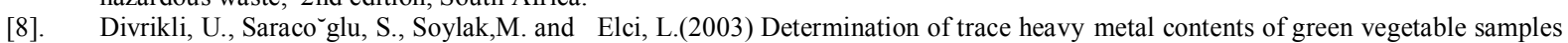
from Kayseri-Turkey by flame Atomic absorption spectrometry, Fresenius Environmental Bulletin, 12, 1123-1125.

[9]. Dosumu, O.O., Salami, N. and Adekola, F.A. (2003) Comparative study of trace elements level in some local vegetable varieties and irrigation waters from different locations in Ilorin, Nigeria. Bulletin of the Chemical Society of Ethiopia, 17(1), 1-6.

[10]. EC Council Directive 98/83/EC of 3 November 1998 on the quality of water intended for human consumption

[11]. Elci, L., Divriklia,U., Akdogana,A., Hola, A., Cetina, A. and Soylak, M. (2010). Selective extraction of chromium(VI) using a leaching procedure with sodium carbonate from some plant leaves, soil and sediment samples. Journal of Hazardous Materials 173 , 778-782

[12]. Erdem, M., Altundogan, H.S., Turan, M.D. and Tumen F. (2005). Hexavalent chromium removal by ferrochromium slag. Journal of Hazardous Materials B. 126, 176-182

[13]. Hattingh, J. and Friend, J.F.C.(2003) Environmental and economic implications of slag disposal practices by the ferrochromium industry: A case study. Water SA, 29 (1), 23- 30

[14]. Huang, S., Peng, B., Yang, Z., Chai, L., Xu, Y.and Su, C.(2009) Spatial distribution of chromium in soils contaminated by chromium-containing slag. Transactions of the Nonferrous Metals Society of China, 19, 756-764

[15]. Ibrahim, M. B.(2008) Atomic Absorption Spectrophotometric Determination of Cr(VI) Levels from Tannery Effluents. Bioscience Research Communications, 20 (6), 293 - 298

[16]. Kilau, H.W. and Shah, I.D. (1984) Prevention chromium leaching from waste slag exposed to simulated acid precipitation: A laboratory study. U.S. Dep. Interior, Bur. Mines, Minneapolis, MN, USA, Report No. 8878, $1-21$.

[17]. Kotas, J. and Stasicka Z. (2000). "Chromium occurrence in the environment and methods of its speciation," Environmental Pollution. Vol. 107, pp. 263-283

[18]. Lind, B.B., Fallman, A.M., and Larsson, L.B.(2001) Environmental impact of ferrochrome slag in road construction. Waste Management, 21(3), 255-264.

[19]. Mahvi, A. H., (2008) Application of agricultural fibers in pollution removal from aqueous solution. International Journal of Environmental Science and Technology, 5 (2), 275-285

[20]. Mandiwana, K.L., Panichev, N. and Ngobeni, P. (2007) Electrothermal atomic absorption spectrometric determination of Cr(VI) during ferrochrome production. Journal of Hazardous Materials, 145: 511- 514.

[21]. Mashanyare, H.P. and Guest, R.N. (1997) The recovery of ferrochrome slag at Zimasco, Mineral. Engineering, 10, 1253- 1260

[22]. Niemelä, P and Kauppi, M.(2005) Formation, Characteristics and Use of Ferrochromium slags. Proceedings of the 4th European Slag Conference of Euroslag. 20-21 June 2005. Oulu Finland.

[23]. Panichev, N., Mandiwana, K.L., Kataeva, M. and Siebert, S(2005) Determination of Cr(VI) in plants by electrothermal atomic absorption spectrometry after leaching with sodium carbonate, Spectrochimica Acta 60B, 699-703.

[24]. Pillay, K., von Blottnitz, H., Petersen, J. (2003) Ageing of chromium(III)-bearing slag and its relation to the atmospheric oxidation of solid chromium(III)-oxide in the presence of calcium oxide. Chemosphere, 52, 1771-1779.

[25]. Pumure, I., Sithole, S.D. and Kahwai, S.G.T.(2003). Characterisation of particulate matter emissions From the Zimbabwe mining and smelting company (Zimasco) Kwekwe division (Zimbabwe): A ferrochrome smelter. Environmental Monitoring and Assessment, 87, 111-121.

[26]. Riekkola-Vanhanen, M. (1999) Finnish expert report on best available techniques in ferrochromium production. The Finnish Environment, 314, 1- 51.

[27]. Sedumedi, H.N., Mandiwana, K.L., Ngobeni, P. and Panichev, N. (2009). Speciation of Cr(VI) in environmental samples in the vicinity of the ferrochrome smelter, Journal of Hazardous Materials, 172, 1686-1689

[28]. Shah, I.D.(1984). Chromium bearing waste slag: evaluation of leachability when exposed to simulated acid rain. In: Jackson, L.P., Rohlik A.R. (Eds.), Third Symposium, Hazardous Industrial Waste Management and Testing, Philadephia. ASTM STP, 851, pp. 61-81.

[29]. Tanskanen, P. A. and Makkonen H.T.(2005) "Applied mineralogy and petrology - examples of useful methods for slag composition and property design", 4th European Slag Conference, Oulu, pp. 71-82.

[30]. Tiwary RK, Dhakate R, Ananda Rao V, Singh VS. 2005. Assessment and prediction of contaminant migration in ground water from chromite waste dump. Environmental Geology. 48, 420-429.

[31]. Wang, Z.X., Chen, J.Q., Chai, L.Y., Yang, Z.H., Huang, S.H., and Zheng, Y. (2011). Environmental impact and site-specific human health risks of chromium in the vicinity of a ferro-alloy manufactory, China. Journal of Hazardous Materials, 190 (1-3), 980 - 985

[32]. Zayed AM and Terry N. 2003. Chromium in the environment: factors affecting biological remediation. Plant and Soil 249: 139156 . 


\section{Author's Profile}

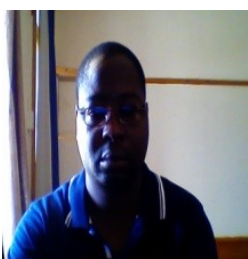

Dr Tawanda Mugadza is a PHD holder in Physical Chemistry from Rhodes University in South Africa. His research interests are focused towards environmental pollutants. He a published a lot of articles on sensor development using phthalocyanine-carbon nanotube conjugates for the electrochemical detection of pesticides. Tawanda is current member of the South African Institute of Chemists (SACI) and ISALS Editorial Board member.

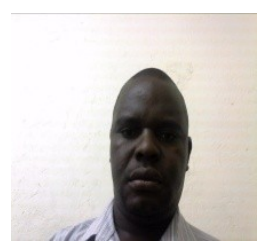

Shadreck Mandina is a BSC, MED and MSC degrees holder from Midlands State University attained in 2004, 2007 and 2012, respectively. During $2004-2009$ he worked as a Teaching assistant in the department of Chemical Technology, Midlands State University. He is currently a Lecturer in the Department of Educational Foundations, Management and Curriculum Studies at Midlands State University in Zimbabwe. 